\title{
Analysis of Tool Life Functions in Hard Turning
}

\author{
János KUNDRÁK, Zoltán PÁLMAI, Gyula VARGA
}

\begin{abstract}
The relation between the technological parameters of cutting and the tool life is important information that has been described by several functions since the publication of the Taylor formula. Although the $v_{c}$-T cutting speed-tool life curve has local extremes, the Taylor formula can describe correctly only its monotone decreasing phase, and this is typical also for the $v_{c}-T$ function proposed by different researchers. This paper describes the results of studies aimed at analysing the relationship proposed by Kundrák and applicable throughout the interval of the $v_{c}-T$ curve. It introduces cutting speed ranges, analyses their boundaries and explores the relationship between constants of the new $v_{c}-T$ formula and the exponent $k$ of the Taylor formula valid for section III. These findings were verified by experiments executed on hardened steel type $100 \mathrm{Cr} 6$ (HRC $60 \pm 2$ ) by K10 type CBN tool.
\end{abstract}

Keywords: general tool life function; hard turning; tool life function; optimization; Taylor exponent

\section{INTRODUCTION}

The cutting tools wear out with intensity depending on the cutting conditions. In order to understand this process researchers are conducting new research $[1,2]$, using new wear measuring methods [3], describing the process $[4,5]$ by modelling [1, 6-8] and monitoring tool wear [6], so that they can determine the tool life more and more accurately.

In the economical optimization of machining, the tool life curve is generally required. This gives the tool life as function of technological parameters, particularly cutting speed. Several researchers have attempted to set up a tool life equation, but the exact knowledge of the functions expressing tool life is still a current issue in cutting theory and technique. The practical significance is high, because the economy of cutting depends, to a great extent, on its correct or incorrect choice.

As is well known, in cutting theory studies [9] and even more so in practical technology, mainly the relationship between certain cutting parameters is examined, most often cutting speed $v_{c}$ and tool life.

Fig. 1 shows types of tool life curves [10] that either show a monotonous (continuous) decrease (curve 1) or a more commonly occurring curve with local extremities (curve 2). Curve 2 can be divided into three distinct sections (Fig. 1). In Fig. $1 T$ is the tool life and $v_{c}$ is the cutting speed.

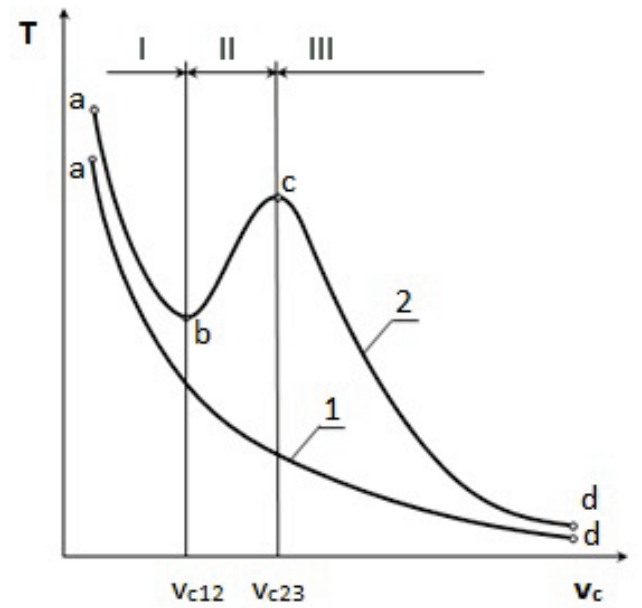

Figure 1 Typical tool life curves: (1) continuously decreasing curve; (2) curve having local extremities
The curve with local extremities makes sense considering that the wear that determines tool life originates during very complex mechanical, chemical, thermal, electrical, etc. processes. If the cutting conditions change, the mechanical and thermal loading of the tool also changes and the ratio of wear components is also modified, which is difficult to handle mathematically. All of this results in a relation between the cutting parameters and tool life that leads to a complicated relationship hardly usable in engineering practice, in a wider range of varying cutting parameters.

Over the years, many suggestions have been made to simplify the function describing the relationship between cutting data and tool life by approximation curves.

F.W. Taylor [11] created his tool life model in 1907, which in its standard form today can be written as follows:

$v_{c} \cdot T^{-\frac{1}{k}}=C_{v}$

where: $T$ - tool life, min; $v_{c}$ - cutting speed; $k$ - tool life exponent; $C_{v}$ - a constant representing the cutting speed that results in 1 min tool life.

The Taylor equation provides data $\left(v_{c}\right.$ or $\left.T\right)$ with satisfactory accuracy in practice for single point cutting tools, when the other two cutting data $\left(a_{p}\right.$ and $\left.f\right)$ are held constant [12]. The Taylor model approximates the real relationship between the cutting speed and the tool life in the $\log v_{c}-\log T$ plane by a straight line (Fig. 2a). The lower the cutting speed range is, within which the relation between $v_{c}$ and $T$ is examined in the branch of the curve descending after the extreme values, the defects results from approximation. Fig. 2 illustrates the measured/real tool life values with dashed curves and with continuous lines the validity range of the tool life equations.

The tool life model developed by Gilbert [13] is essentially an extension of the Taylor model, considering the effect of feed and depth of cut. Since the Gilbert model is an extended Taylor model, here also the real $T-v_{c}$ curve is replaced by straight line on the $\log v_{c}-\log T$. The imaging of the relationship to the plane $T-v_{c}$, in accordance with the effect of the feed and the depth of cut provides numerous straight lines, each of which represents a feed or depth of cut where, besides the cutting speed, the other cutting data are constant (Fig. 2b). 
As regards the cutting of alloyed materials used in increasing quantities by carbide and ceramic tools, the correlation between $T$ and $v_{c}$ is not linear moreover in log $\log$ planes according to the observations. Therefore,
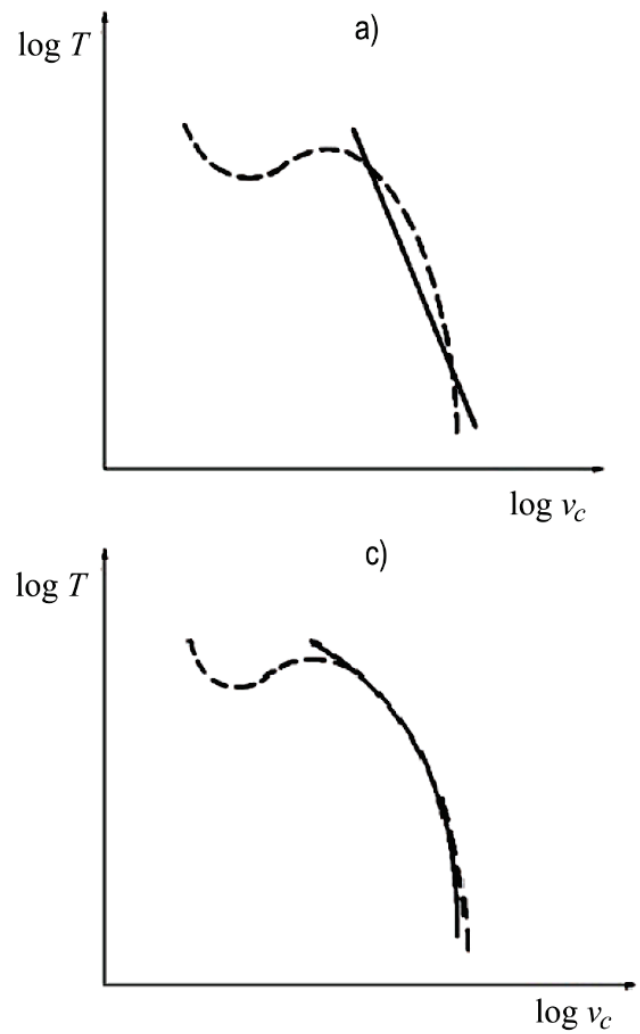

Figure 2 Different empirical approaches to the $v_{c}-T$ tool life curve: a) Taylor [11]; b) Gilbert [13]; c) König-Deperieux [14]; d) Kronenberg [15];

Solid lines indicate the range of applicability.

König and Depiereux [14] started from the point that the correlation between the cutting speed and the tool life is described by a curve in the $\log v_{c}-\log T$ coordinate system which, by some modification of the simple Taylor equation - adding a constant to the cutting speed - can be approached with the following function:

$$
T=\frac{C_{T 1}}{\left(v_{c}+C_{T 2}\right)^{C_{T 3}}}
$$

The nature of the model is given in Fig. 2c. The tool life model developed by Kronenberg [15] can be described as follows:

$$
T=C_{T 1} \cdot \mathrm{e}^{C_{T 2} \cdot v_{c}^{C_{T 3}}+C_{T 4} \cdot f} C_{T 5}
$$

This model, besides cutting speed $v_{c}$, considers the effect of feed $f$ on tool life. Due to its exponential shape, it represents well those physical and chemical processes that cause wear of the tool (Fig. 2d).

Some more models are mentioned here. The tool life model of Safonov [16], similarly to the König-Depiereux model, is exponential shaped, and considers the influence of cutting speed only at the constant value of the other cutting data: models have been proposed that describe the curved section not as logarithmic line, but more accurately with a higher order function relation.

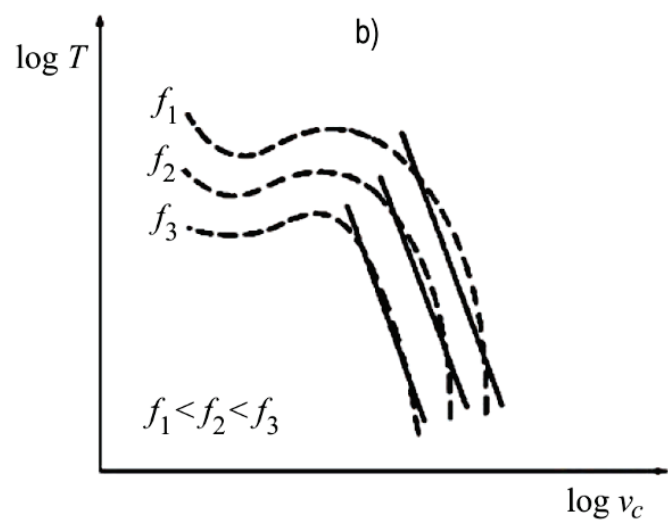

d)

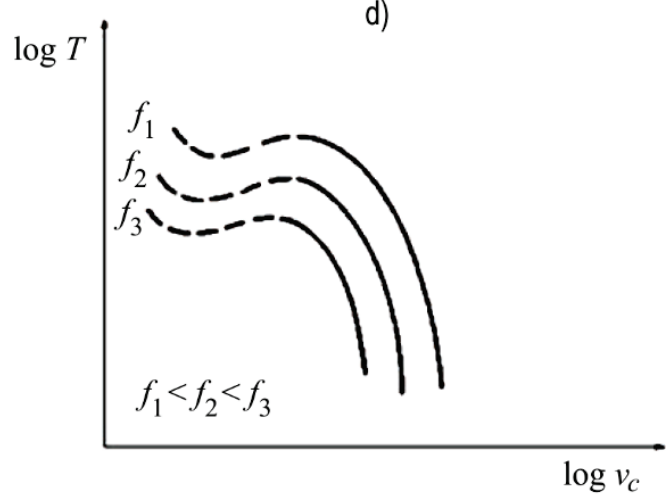

$T=\frac{C_{T 1}}{\mathrm{e}^{C_{T 2} \cdot v_{c}}}$

Temcsin's tool life model [17] is most like the Kronenberg model:

$T=\frac{C_{T 1}}{v_{c}^{C_{T 2}}+C_{T 3}}$

The Wu type tool life model [18] shows a degree of similarity with the simple Taylor model, the difference being in the complex power output of the cutting speed, which itself includes the cutting speed:

$T=\frac{C_{T 1}}{v_{c}^{C_{T 2}+C_{T 3} \cdot v_{c}}}$

Even in systematic, in-depth studies, if differences were observed across the entire speed range, these differing values (perhaps because of simplification) were often considered as greater standard deviation, while other researchers have taken the differences into account and attempted to describe relationships mathematically as well.

The tool model developed by Colding [19] belongs to the second order models that follow well the flow of $T-v_{c}$ curves in a wide cutting speed range, which is realized by considering both the linear and quadratic members of the 
technological data and their multiplication. The method is still used today, as can be seen in the work of Thaker et al. [20] and Busham [21], where the multiplication of cutting factors is also considered in the tool life function without paying attention to the extreme values of this curve.

The tool life model of Granovskij [22] shows a difference from the previous formulae in considering the effect of technological data (cutting speed) in its coefficients, too:

$$
T=C_{T 1} \cdot v_{c}^{C_{T 2}} \cdot C_{T 3}^{C_{T} 4 \cdot v_{c}}
$$

It is interesting that even a large-scale study, such as that of Colding and König [23] on the Taylor equation, is practically confined only to section III shown in Fig. 1 and provides well-established calculations related to it for the determination of optimal cutting parameters. In fact, these less-than-satisfactory equations are still used. For instance, when Galoppi et al. [24] evaluate the results of their hardturning experiments, the measurement results are reported obviously by reference to the Taylor formula in a specific technological situation. The problem of local extremity is not even raised. Also, Abburi and Dix [25] are still focusing only on the examination of section III.

However, today an increasing number of cutting researchers are coming to accept the fact that the $v_{c}$-T tool life relationship, in most concrete cases, is correctly characterized by Curve 2 in Fig. 1 in which three sections must be definitely separated. Benga and Abrao [26], in their study of hard turning, for example, report experimental results falling in the difficult to model border zone of section II and III. Punta and Hryniewicz [27] studied the full range of curve 2 in Fig. 1, analysing in detail the extreme value sites separating the three sections of the curve by mathematical methods. Vasilko's proposal considers the above-mentioned nature of the tool life curve [28].

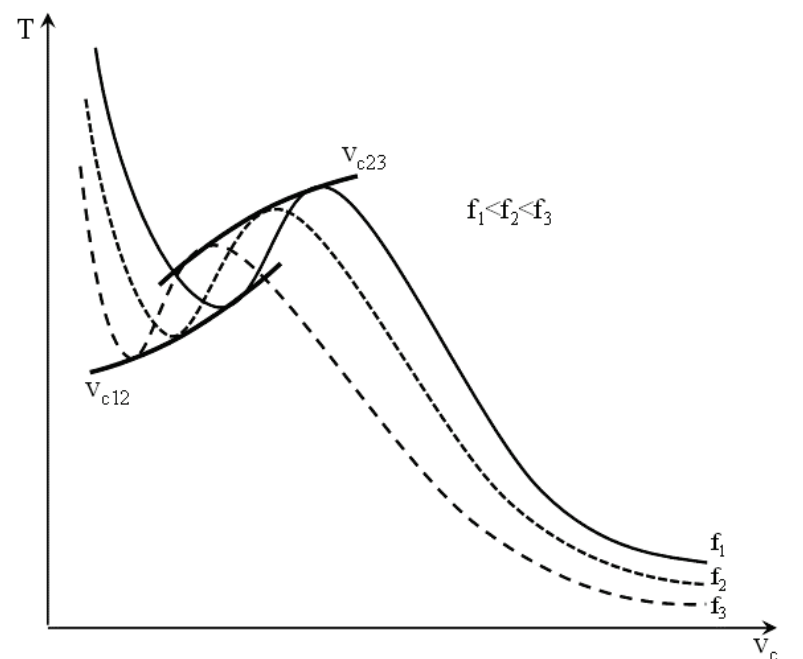

Figure 3 The effect of feed rate on the extreme values of the $v_{c}-T$ curve

Fig. 3 shows the $v_{c}$ - $T$ curve at three different feed rates. A closer look at the tool life curves reveals that the slopes of the curves do not differ significantly, but the range limit is significantly influenced by the cutting data - here feed rate, but other parameters can have a similar effect [29]. It may occur that for a given feed rate - depth of cut combination a certain speed may be optimal, while in other combinations it results in unfavourable tool life.

In section III of the tool life curve (see Fig. 1), from the local maxima towards higher cutting speeds, the Taylor formula can provide a reasonable approximation. However, within the range of smaller cutting speed values that fall into section II, the Taylor exponent k significantly differs from the actual tool life value. Taylor's version assumes that, in the case of all tool-workpiece pairs, tool life varies in the same way depending on the speed, which would mean that it changes in the same manner as the temperature. (This is clearly not true - think e.g. of the ironcarbon state diagram.) In section II the Taylor equation cannot be recommended. In the lowest speed range (section I), the difference between values calculated with the Taylor formula and actual values is even more significant.

A manageable tool life function is needed that is suitable for describing all three sections of the tool life curve. In an attempt to meet this need, a general tool life model was first proposed by Kundrák in his 1996 dissertation [29]. It is intended to better describe the tool life of modern tool materials, when there is a local minimum and maximum depending on the cutting parameters. As a function of speed $v_{c}$, the tool life $T$ is:

$$
T=\frac{C_{T 1}}{v_{c}^{3}+C_{T 2} \cdot v_{c}^{2}+C_{T 3} \cdot v_{c}}
$$

Advantages of the Kundrák formula (Eq. (8)) have been explored in detail in $[10,30]$ but its favourable features can be summarized as follows: in the full cutting speed range it reflects the physical laws of the cutting process more accurately, by expressing the exact location and value of the extremities at $v_{12}$ and $v_{23}$ cutting speeds, considering the joint effect of the cutting parameters (Fig. 3). This means that it has a much broader range of applicability, throughout all sections of the tool life curve, because it:

- provides a more accurate possibility of calculation for the full speed range,

- is a simple calculation,

- helps to determine the validity range for the Taylor formula,

- helps the application of combined tools (rotating, working with division of depth of cut, etc.),

- makes optimization more accurate, since the search scope can be assigned more accurately,

- allows maximum tool life value to be determined with different combinations of parameters.

\section{EXAMINATION OF THE TAYLOR EXPONENT}

It is common to say that the Taylor exponent is the slope of the $v_{c}$ - $T$ tool life curve, although it only appears to be so due to the log-log scale. The slope of the tool life curve, which is ultimately characterized by the $\mathrm{d} T / \mathrm{d} t$ differential ratio, has an interesting connection with the $-k$ exponent. The Kundrák formula gives exactly the surplus that follows the curvature of the real $v_{c}$ - $T$ function section III.

From Taylor Eq. (1)

$\frac{\mathrm{d} T}{\mathrm{~d} v}=k \cdot C^{-k} \cdot v_{c}^{k-1}=k \cdot T / v_{c}$ 
Where

$k=\frac{v_{c}}{T} \cdot \frac{\mathrm{d} T}{\mathrm{~d} v}$

Eq. (8) is derived according to $v$

$$
\frac{\mathrm{d} T}{\mathrm{~d} v}=-\frac{\left(3 v_{c}^{2}+2 C_{T 2} v_{c}+C_{T 3}\right)}{C_{T 1}} T^{2}
$$

which can be substituted into Eq. (10), so

$$
-k(v)=\frac{\left(3 v_{c}^{2}+2 C_{T 2} v_{c}+C_{T 3}\right) v_{c}}{C_{T 1}} T
$$

Eq. (10) is interesting because if functions $\mathrm{d} T(v) / \mathrm{d} t$ and $T(v)$ are known, the exponent can be determined at any section of the curve, as is done here by using formula (8). Of course, in every case where the exponent is function of $k=k(v)$, the "constant" $C$ is also used as a $C=C(v)$ function, according to Eq. (1).

\section{VALIDATION OF THE THEORETICAL FUNCTION $k(v)$}

The cutting tests performed earlier were done by turning inner cylindrical surfaces made of hardened steel $100 \mathrm{Cr} 6$ (HRC $62 \pm 2$ ) with $D=45,75$ or 100 -mm diameter. The tool was of K10 quality $\mathrm{CBN}$ tool with the edge geometry: $\gamma=-5^{\circ}, \alpha=\alpha^{\prime}=15^{\circ}, \lambda_{s}=0^{\circ}, \kappa_{r}=45^{\circ}, \kappa_{r}^{\prime}=15^{\circ}$. Cutting data: $v_{c}=11-120 \mathrm{~m} / \mathrm{min}$, feed rate $f=0.05 \mathrm{~mm} / \mathrm{rev}$, depth of cut $a=0.15 \mathrm{~mm}$. The results of the tool life tests are summarized in Tab. 1. Based on these, constants of the tool life Eq. (8), which are given in Tab. 2, could be determined. Fig. 4a shows the tool life curves $v_{c}-T$ calculated with these constants. The curves fit well on the

\begin{tabular}{|c|c|c|c|c|c|c|c|c|c|}
\hline \multirow{3}{*}{$D / \mathrm{mm}$} & \multicolumn{9}{|c|}{$v_{c} / \mathrm{m} / \mathrm{min}$} \\
\hline & 11 & 20 & 29 & 40 & 50 & 68 & 92 & 105 & 120 \\
\hline & \multicolumn{9}{|c|}{$T / \min$} \\
\hline 45 & 153 & 145 & 181 & 143 & 65 & 17 & 7 & 4 & 3 \\
\hline 75 & 206 & 189 & 221 & 211 & 113 & 33 & 10 & 7 & 4 \\
\hline 100 & 250 & 222 & 254 & 261 & 159 & 41 & 14 & 7 & 5 \\
\hline
\end{tabular}
experimental results.
The range of the cutting speed used in the tests was considerably wider than the range for which the Taylor formula is applicable. This is particularly striking in Figure 4/a, which describes the $v_{c}-T$ function connection on a linear scale, but also in the curves drawn on the normal loglog plane (Fig. 4b) it can be seen that the Taylor formula can be used only from $v_{c} \geq 40 \mathrm{~m} / \mathrm{min}$ and this is the lower speed limit of its usability (its value depends on the technological parameters as well).

Here, the diameter $D$ of the workpiece is a parameter that affects this speed limit, as was already mentioned for Fig. 3. Therefore, in the present case, it is advisable to carry out the examination of Taylor exponent test from $v_{c} \approx 40$ $\mathrm{m} / \mathrm{min}$.

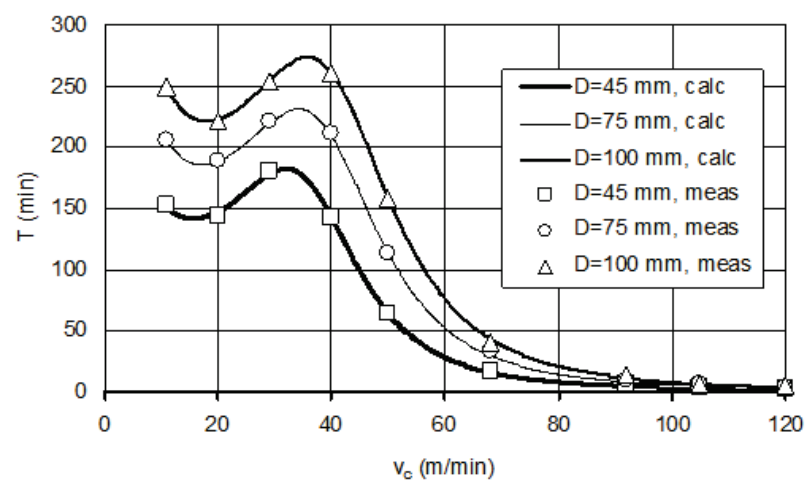

a)

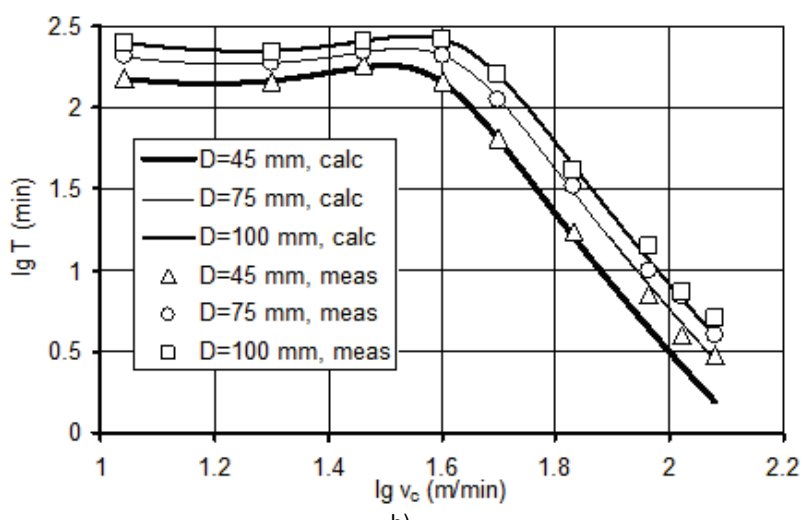

b)

Figure 4 Comparison of calculated tool life curve using the Kundrák formula and measured values (a) and the logarithmic shape of the tool life curve (b)

Table 2 Constants of the tool life function for Eq. (8)

\begin{tabular}{|c|c|c|c|}
\hline$D / \mathrm{mm}$ & $\mathrm{C}_{T 1}$ & $\mathrm{C}_{T 2}$ & $\mathrm{C}_{T 3}$ \\
\hline 45 & $1.38 \times 10^{6}$ & -71.3 & 1494 \\
\hline 75 & $2.33 \times 10^{6}$ & -76.9 & 1755 \\
\hline 100 & $3.181 \times 0^{6}$ & -80.45 & 1923 \\
\hline
\end{tabular}

In Fig. 5, the straight-line $\log v-\log T$ and its regression equation, both measured and calculated by Eq. (8) and Eq. (12) can be seen for $D=100 \mathrm{~mm}$. The other two equations for the examined diameter and $R^{2}$ are shown in Tab. 3 in order not to disturb the clarity of the figure.

Table 3 Regression equations $\log v-\log T$, measured and calculated by the Kundrák formula

\begin{tabular}{|c|c|c|c|}
\hline \multirow{2}{*}{$D / \mathrm{mm}$} & \multicolumn{2}{|c|}{ Measured $T / \min$} & \multicolumn{2}{c|}{ Regression equation $\log v-\log T$} \\
\cline { 2 - 4 } & $\begin{array}{c}\text { Regression equation } \\
\log v-\log T\end{array}$ & $R^{2}$ & calculated by Kundrák formula $T /$ min \\
\hline 45 & $-3.7947 \log v+8.2399$ & 0.9960 & $-4.1401 \log v+9.2054$ \\
\hline 75 & $-3.6694 \log v+8.2386$ & 0.9978 & $-4.1892 \log v+9.1445$ \\
\hline 100 & $-3.7679 \log v+8.5188$ & 0.9938 & $-4.2564 \log v--9.0152$ \\
\hline
\end{tabular}




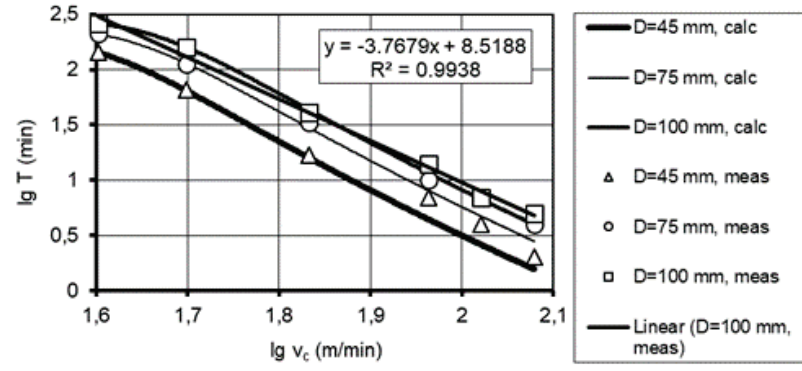

Figure 5 Monotone reducing section of tool life curves calculated by Kundrák's formula

The close fitting of the tool life calculated by the Taylor and the Kundrák formula and the measured tool life can be directly determined from Fig. 6, which convincingly supports the hypothesis that in determining the specific velocity-dependent values of the Taylor exponent, Eq. (12) derived from the two tool life functions can indeed be used.

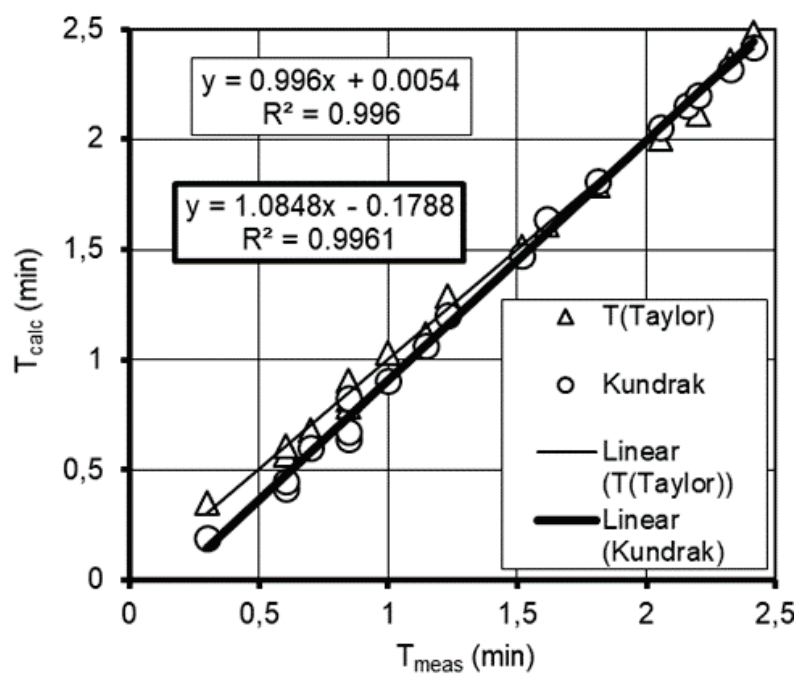

Figure 6 The fitting of tool life calculated by the Taylor and Kundrák formulas to measurements

It is worth noting that the range of the cutting speed to which the Kundrák formula can be applied is significantly higher; the constants summarized in Tab. 2 are defined for this entire speed interval. In the entire investigated cutting speed range of curve $v_{c}$ - $T$, which is more complicated then, which is too complicated to be handled at all with the Taylor formula, as it can be seen in Fig. 4.

\section{$4 \quad$ FUNCTION - $k(v)$}

The characteristic sections of the curve $v_{c}-T$ are described by the function $\mathrm{d} T / \mathrm{d} v$ defined by Eq. (5). This is shown in Fig. 7 for the full tool life curve.

The value of the Taylor exponent for the three diameters can be calculated from Eq. (12). The results are summarized in Fig. 8, which shows that $-k$ really depends on the cutting speed $v_{c}$. Conversely, the exponents based on the Taylor formula are constants and, at $D=45,75$ and 100 are $-k=3.7947 ; 3.6694$ and 3.7679 , respectively.

Of course, this cutting speed dependent $-k$ exponent also implies that the $C_{v}$ constant of the Taylor formula is not constant, as shown in Fig. 9. In the first two sections of the full $v_{c}-T$ curve (Fig. 1), where there are the extremities (first minimum and then maximum), in principle the function $C\left(v_{c}\right)$ can be calculated, but it is practically unusable, as it varies between $\pm \infty$. In section III of the $v_{c}-T$ curve, where the function becomes monotonically decreasing, the value of Taylor's "constant" $C_{v}$ is formed as shown in Fig. 9.

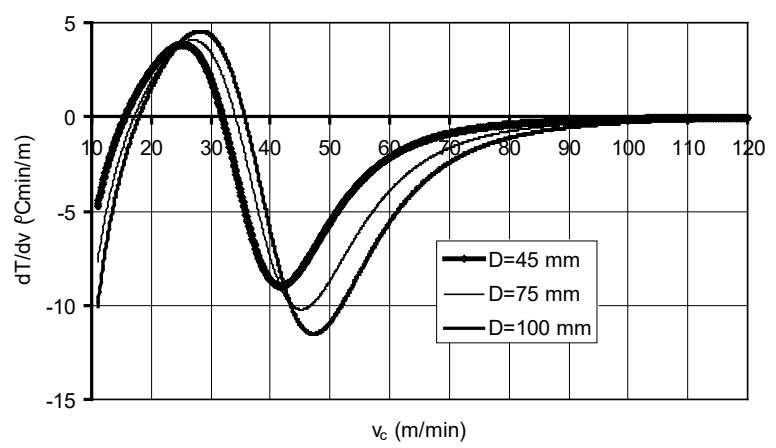

Figure 7 Function $\mathrm{d} T / \mathrm{d} v$ at different workpiece diameters

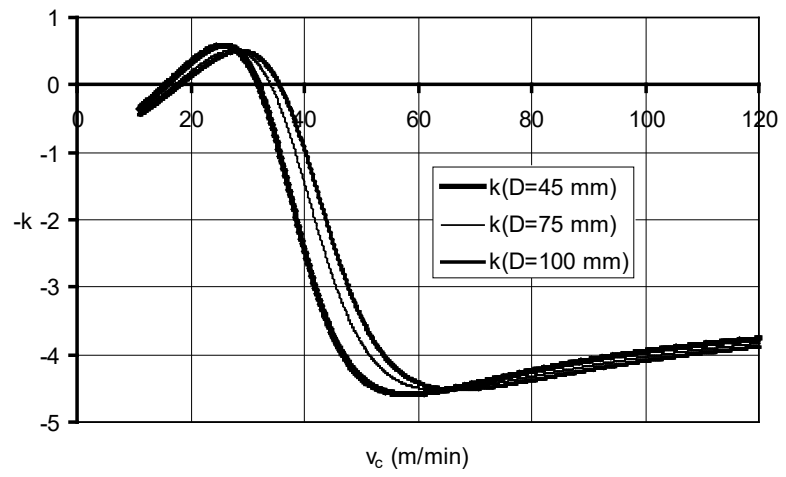

Figure 8 Real change of the Taylor exponent as a function of cutting speed at different workpiece diameters

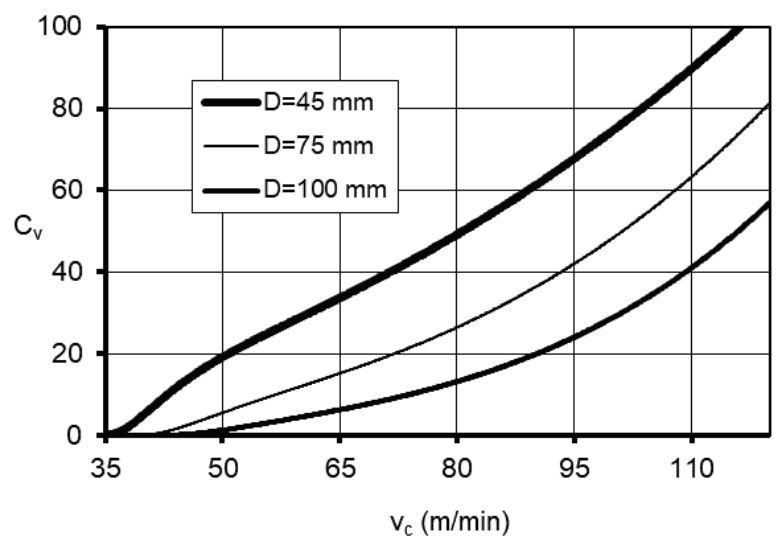

Figure 9 The values of $C_{v}$ "constant" of the Taylor formula calculated from equation (12) and considering $-k$ exponents

Consequently, it is worth checking the usual formulas for calculating optimal cutting parameters using the Taylor formula-based extremum calculation; it is recommended to calculate the optimum cutting parameters from the real $v_{c}-T$ curve. These values may occasionally differ significantly from the results of the Taylor constants calculation.

\section{APPLICATION}

The new tool life function is suitable for all practical tasks that have previously used the Taylor formula and other $T\left(v_{c}\right)$ functions. In addition, the function has the advantage that it can be used over the whole range 
(interval, spectrum, ...) of the $v_{c}$ cutting speed used in practice. First of all, it is useful in planning the optimum technological parameters. Whether the task is to minimize the cost or to maximize the power of chip removal, the search for the optimum is not restricted to Section III only. As an example, for the hard turning of an inner cylindrical surface of diameter $D=100 \mathrm{~mm}$ or $45 \mathrm{~mm}$, the data of chip cross section can be calculated using the data in Tab. 3. The main data of the economy calculation are the machine's cost per minute: $k_{m}, € / \mathrm{min}$, the edge cost of the tool $E_{\text {tool }}, €$; while in the case of calculating the chip removing power, the time needed to exchange tools or reassemble the cutting tool $t_{c h}$ is essential.

Using the latter, the chip removing power is

$$
P=a \cdot f \frac{v_{c} \cdot T}{t_{\mathrm{ch}}+T}
$$

which, as is known from the calculation based on the Taylor formula, has the maximum tool life

$$
T_{P \mathrm{opt}}=(-k-1) \cdot t_{\mathrm{ch}}
$$

for which the cutting speed $v_{P o p t}$ can be calculated from the Taylor formula. This method is not applicable any more. The meaning of the letters in Eq. (13): $P$ - chip removing power; $a$ - depth of cut; $f$ - feed, $t_{\mathrm{ch}}$ - tool exchange time.

Using the parameters given in Tab. 3 the function $P$ of the power of chip removal is shown in Fig. 10, when diameter is $100 \mathrm{~mm}$. It can be seen that the two calculations have their maximums at different speeds, and that the magnitude of these maximums is different for the two calculations. In the case of a longer tool exchange time, the application of Kundrák's formula, which is closer to the real shape of $v_{c}-T$ curve, represents higher productivity, while with decreasing tool exchange time, this difference decreases and even becomes a sign of contradiction. It can be observed that, in the former case, the optimum cutting speed moves downward with increasing replacement time, to the range in which the $-k$ real Taylor exponent deviates more and more from the average exponent, which is independent from $v$ of the Taylor formula. From this it can be concluded that in the lower speed range the power function derived from the Kundrák model gives the more realistic result. Of course, here we are talking about relating and comparing two models that work close to the actual cutting conditions. Ultimately, in this application example, the two optimums provide roughly the same result from the point of view of chip removal performance. Fig. 3, however, warns that changing the technological parameters can easily shift the cutting process in a direction where the Taylor formula is no longer valid and strongly distorts the economic calculations.

To determine the cutting speed that is economical from the point of view of tool life, it is expedient to examine the chip removal cost of the unit material volume, which is

$$
E=\frac{1}{a \cdot f \cdot v}\left(k_{m}+\frac{t_{\mathrm{ch}} \cdot k_{m}-E_{\mathrm{tool}}}{T}\right)
$$

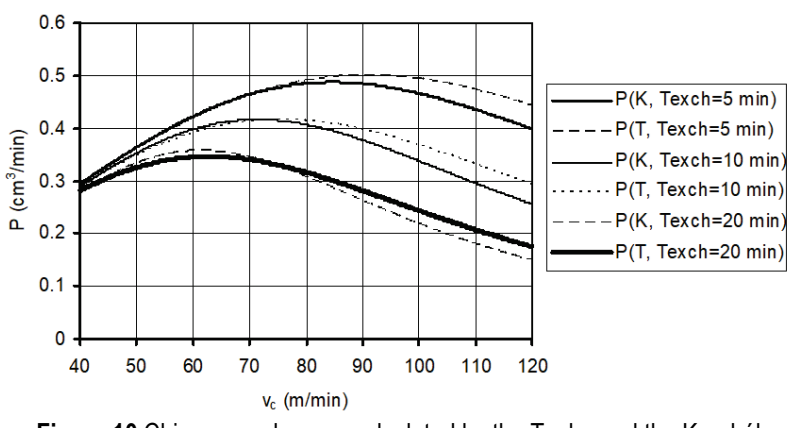

Figure 10 Chip removal power calculated by the Taylor and the Kundrák formulas at different tool exchange times

Calculating by the generalized tool life function, the cost per unit of the removed material volume is shown in Fig. 11 as a function of speed.

Of course, the curves of Fig. 11 are also fundamentally influenced by the technological parameters. The cost of the edge of the tool is particularly important for this calculation, as shown in Fig. 12.

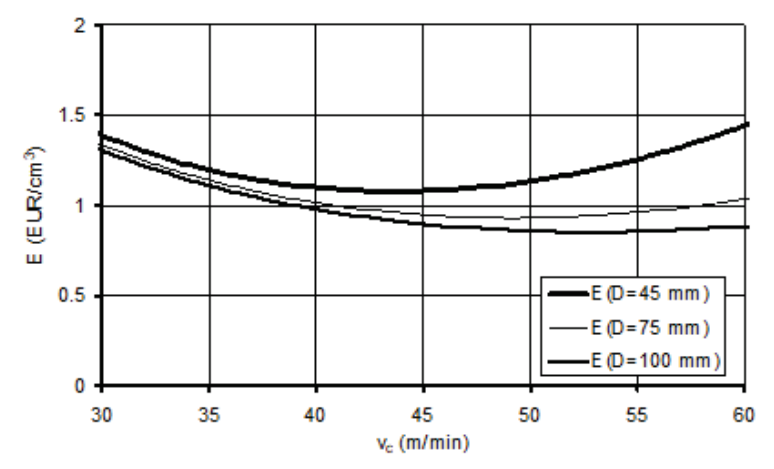

Figure 11 Specific cost calculated by the Kundrák formula in manufacturing holes of different diameters $\left(k_{m}=0.25 € / \mathrm{min}, E_{\text {tool }}=10 € /\right.$ edge, $\left.t_{c h}=5 \mathrm{~min}\right)$

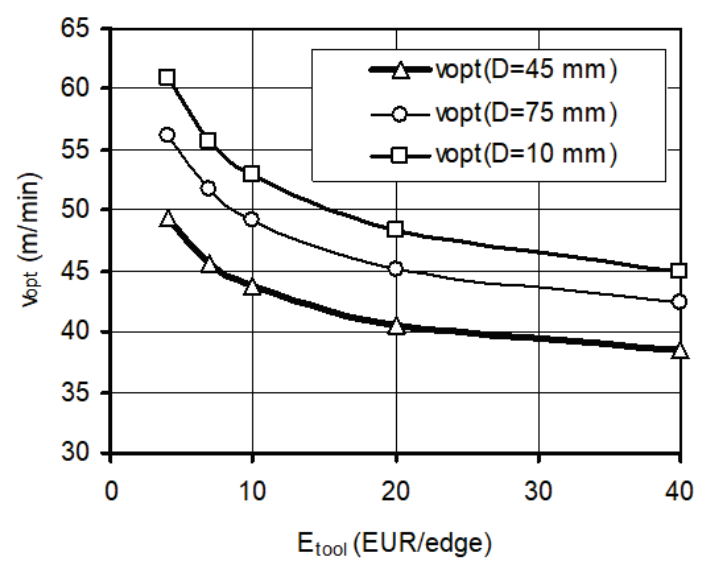

Figure 12 Cutting speed $v$ related to optimum cost as function of edge cost of the tool $E_{\text {tool }}$

For the workpiece $D=45 \mathrm{~mm}$, the optimum cutting speed is now below $v_{c}=40 \mathrm{~m} / \mathrm{min}$, which is already the zone where the Taylor formula will produce serious errors (cannot provide an accurate value), as shown in Fig. 1.

\section{SUMMARIES}

The cutting-edge tool life of the cutting tool is important information for technological design and optimization, so since Taylor's original formula there have been several proposals for mathematical description of the impact of technological parameters affecting tool life. The 
vast majority of the proposed functions do not take into account that the general $v_{c}-T$ curve has local extremes and, like the Taylor formula, apply only to the monotonous decreasing section. In the context of the local extremes of the $v_{c}-T$ curve, traditional optimization of the cutting process can lead to incorrect results. Taylor's exponent is a function of the technological parameters, and in the environment of the extremes in the $v_{c}-T$ curve, it even changes its sign, so the optimization is strongly distorted. The tool life algorithm proposed by Kundrák can describe the entire range of the tool life curve, specifying the local minimum, maximum location and value. These are influenced by technological parameters, and their effect can be described in detail and the validity range for the Taylor function can also be specified. For the analysis of the relationships we also carried out cutting experiments. The machining experiments were performed on hardened steel 100Cr6 with a K10 CBN tool insert at a speed range of $v_{c}=11-120 \mathrm{~m} / \mathrm{min}, f=0.05 \mathrm{~mm} / \mathrm{rev}, a=0.15 \mathrm{~mm}$. Based on the analysis of the tool life measurements performed in the D45-D100 mm hole during hard turning, the following results can be summarized.

a) It is confirmed that the third-order rational fraction function proposed by Kundrák for describing the $v_{c}-T$ relationship can be applied over the entire interval (range) of $v_{c}$ cutting speeds under the assumptions examined.

b) We defined the boundary coordinates of the three sections of the $v_{c}-T$ formula with the constants of the new function. These are influenced by technological parameters in a specific way.

c) We found that there is a close relationship between the constants of the new $v_{c}-T$ formula and the $k$ exponent of the Taylor formula valid in Section III.

d) The experiments showed that the Kundrák formula fits the measurement results well over the full range of the test speed, while the Taylor formula can only be used in section III of the $v_{c}-T$ curve.

The theoretical results of the research can be directly applied in practice. The optimum technology parameters for operating costs or cutting performance can be determined over the entire $v_{c}$ range.

\section{Acknowledgements}

Project no. NKFI-125117 has been implemented with the support provided from the National Research, Development and Innovation Fund of Hungary, financed under the K_17 funding scheme.

In addition, the described study was carried out as part of the EFOP-3.6.1-16-00011 "Younger and Renewing University - Innovative Knowledge City - institutional development of the University of Miskolc aiming at intelligent specialization" project implemented in the framework of the Szechenyi 2020 program. The realization of this project is supported by the European Union, cofinanced by the European Social Fund.

\section{REFERENCES}

[1] Oraby, S. E. \& Hayhurst, D. R. (2004). Tool life determination based on the measurement of wear and tool force ratio variation, International Journal of Machine Tools \& Manufacture, 44, 1261-1269. https://doi.org/10.1016/j.jimachtools.2004.04.018

[2] Majerík, J., Dubovská, R., Jambor, J., Čep, R., Kratochvíl, J., \& Kouřil K. (2018). Experimental Investigation into Wear and Tool Life of Milling Cutter PVD Coated Carbide Inserts While Armox 500 Steel Hard Milling, Technical Gazette, 25(6), 1603-1610. https://doi.org/10.17559/TV-20161128094553

[3] Vasváry, L., Ditrói, F., Takács, S., Szabó, Z., Szücs, J., Kundrák, J., \& Mahunka, I. (1994). Wear measurement of the cutting edge of superhard turning tools using TLA technique, Nuclear Inst. and Methods in Physics Research, 85(1-4), 255-259. https://doi.org/10.1016/0168-583X(94)95822-X

[4] Królczyk, G., Gajek, M., \& Legutko, S. (2013). Effect of the cutting parameters impact on tool life in duplex stainlesssteel turning process, Technical Gazette, 20(4), 587-592.

[5] Nicolodi, J. H. W., Consalter, L. A., Durán, O., \& Souza, A. J. (2019). Influence of Cutting Speed and Feed Rate on the Wear of an S-Type Mixed Ceramic Tool in Turning of AISI 4140 Hardened Steel, Technical Gazette, 26(4), 913-919. https://doi.org/10.17559/TV-20170920194959

[6] Antić, A., Šimunović, G., Šarić, T., Milošević, M., \& Ficko, M. (2013). A model of tool wear monitoring system for turning, Technical Gazette, 20(2), 247-254.

[7] Tamang, S. K. \& Chandrasekaran, M. (2015). Modeling and optimization of parameters for minimizing surface roughness and tool wear in turning $\mathrm{Al} / \mathrm{SiCp} \mathrm{MMC}$, using conventional and soft computing techniques. Advances in Production Engineering \& Management, 10(2), 59-72. http://dx.doi.org/10.14743/apem2015.2.192

[8] Kim S. J. (2016). Integration of Pre-Simulation and Sensorless Monitoring for Smart Mould Machining, International Journal of Simulation Modelling, 15(4), 623636. http://dx.doi.org/10.2507/IJSIMM15(4)4.354

[9] Shaw, M. C. (2004). Metal Cutting Principles, Oxford University Press Inc,

[10] Mamalis, A. G., Kundrák, J., \& Horváth, M. (2002). Wear and Tool Life of CBN Cutting Tools. International Journal of Advanced Manufacturing Technology, 20, 475-479. https://doi.org/10.1007/s001700200180

[11] Taylor, F. W. (1907). On the art of cutting metals. Trans. ASME, 28, 31-279.

[12] Trent, E. M. \& Wright, P. K. (2000). Metal cutting, 4th ed. Boston, Butterworth Heinemann

[13] Gilbert, W. W. (1950). Economics of machining. In: Machining - Theory and Practice. American Society for Metals, 465-485.

[14] König, W. \& Depiereux, W. R. (1969). Wie lassen sich Vorschub und Schnittgeschwindigkeit optimieren? IndustrieAnzeiger, 91(61), 1481-1484.

[15] Kronenberg, M. (1970). Replacing the Taylor formula by a new tool life equation, International Journal of Machine Tool Design and Research, 10, 193-202.

Research, 10, 193-202. https://doi.org/10.1016/0020-7357(70)90006-5

[16] Enache, S., Dorin, A., \& Strajescu, E. (1976). Contribution concernant l'etablissement des conditions de coupe, Annals of the CIRP, 25(1), 45-48.

[17] Temcsin, G. I. (1957). Multiple Tooling, Theory and Calculation (in Russian), Masgiz, 543.

[18] Wu, S. M. (1964). Tool-life testing by response surface methodology, Parts 1 and 2, Journal of Manufacturing Science and Engineering, 86,105-116. https://doi.org/10.1115/1.3670464

[19] Colding B. N. (1958). A three-dimensional, tool-life equation: machining economics, New York, N.Y., ASME,

[20] Thaker, D. G., Ramamoorthy, B., \& Vijayaraghavan L. (2012). Effect of cutting parameters on the degree of work hardening and tool life during high-speed machining of Inconel 718. Int. J. Adv. Manuf. Technol., 59, 483-489. https://doi.org/10.1007/s00170-011-3529-6 
[21] Bhusham, R. K. (2013). Optimization of cutting parameters for minimizing power consumption and maximizing tool life during machining of $\mathrm{Al}$ alloy $\mathrm{SiC}$ particle composites. Journal of Cleaner Production, 39, 242-254. https://doi.org/10.1016/j.jclepro.2012.08.008.

[22] Granovszkij, G. I. (1965). Stojkosti instrumenta kak ichodno parametra dlja racchota rezhimov rezanija, Vestnik masinostroenija, 8.

[23] Colding, B., \& König, W. (1971). Validity of the Taylor Equation in Metal Cutting. Annals of the CIRP, XVIV, 793812.

[24] Galoppi, G. S., Filho, M. S., \& Batalha, G. F. (2006). Hard turning of tempered DIN 100Cr6 steel with coated and no coated CBN inserts. Journal of Materials Processing Technology, 179, 146-153. https://doi.org/10.1016/j.jmatprotec.2006.03.067

[25] Abburi, N. R. \& Dixit, U. S. (2007). Multi-objective optimization of multipass turning processes. Int. J. Adv. Manuf. Technol., 32, 902-910. https://doi.org/10.1007/s00170-006-0425-6

[26] Benga, G. C. \& Abrao, A. M. (2003). Turning of hardened $100 \mathrm{Cr} 6$ bearing steel with ceramic PCBN cutting tools, Journal Materials Processing Technology, 143-144, 237241. https://doi.org/10.1016/S0924-0136(03)00346-7

[27] Pluta, Z. \& Hryniewicz, T. (2010) Advanced model of the tool edge blunting under machining. Int. J. Adv. Manuf. Technol. 51, 35-43. https://doi.org/10.1007/s00170-010-2595-5

[28] Vasilko, K. (2017). Taylor Equation of Durability and Its Modification, Manufacturing Technology, 17(3), 393-397.

[29] Kundrák, J. (1996). The Scientific Principles of Increasing the Effectiveness of Inner Surfaces Cutting with CBN Tools, DSc dissertation, Kharkov, 368. https://doi.org/10.1016/S0924-0136(03)00346-7

[30] Mamalis, A. G., Kundrak, J., \& Horvath, M. (2005). On a novel tool life relation for precision cutting tools, Journal of Manufacturing Science and Engineering, 127(2), 328-332. https://doi.org/10.1115/1.1794158

\section{Contact information:}

János KUNDRÁK, Prof., DSc,

(Corresponding author)

University of Miskolc

Institute of Manufacturing Science

$\mathrm{H}-3515$ Miskolc, Egyetemvaros

Hungary

janos.kundrak@uni-miskolc.hu

Zoltán PÁLMAI, Prof. C.Sc.

University of Miskolc

Institute of Manufacturing Science

H-3515 Miskolc, Egyetemvaros

Hungary

palmayz@t-online.hu

Gyula VARGA, Assoc. Prof., PhD

University of Miskolc

Institute of Manufacturing Science

H-3515 Miskolc, Egyetemvaros

Hungary

gyulavarga@uni-miskolc.hu 